\title{
Significant elevation of CLDN16 and HAPLN3 gene expression in human breast cancer
}

\author{
SHOU-JEN KUO ${ }^{1,4}$, SU-YU CHIEN ${ }^{2}$, CHE LIN $^{1}$, SZU-ERH CHAN ${ }^{3}$, HSIU-TING TSAI $^{5,6}$ and DAR-REN CHEN ${ }^{1}$ \\ ${ }^{1}$ Comprehensive Breast Cancer Center, Departments of ${ }^{2}$ Pharmacy, and ${ }^{3}$ Surgical Medicine, Erlin Branch, Changhua \\ Christian Hospital, Changhua; ${ }^{4}$ College of Health Care and Management, ${ }^{5}$ School of Nursing, Chung Shan Medical \\ University, Taichung; ${ }^{6}$ Department of Nursing, Chung Shan Medical University Hospital, Taichung, Taiwan
}

Received February 24, 2010; Accepted April 29, 2010

DOI: $10.3892 /$ or_00000918

\begin{abstract}
Cancer development involves the destruction of tight junctions, deprivation of cell polarity, and increased cell mobility. Claudin 16 (CLDN16) is a tight junction protein and plays important roles in the maintenance of cell polarity, cellular arrangement, adhesion, paracellular transport, and ionic permeability of various epithelia. A novel link protein, HAPLN3, functions in hyaluronic acid binding and cell adhesion. Both genes are hypothesized to be related to cancer development and metastasis. The purpose of this study was to estimate the roles of the genes CLDN16 and HAPLN3 in breast cancer. A total of 146 samples were collected from breast cancer tissues and their adjacent normal breast tissues. Reverse transcription and real-time polymerase chain reaction were used to estimate gene expression levels. There were significantly increased gene expression of CLDN16 $(\mathrm{p}<0.0001)$ and HAPLN3 $(\mathrm{p}<0.0001)$ among breast cancer tissues compared with normal tissues, irrespective of clinical pathological parameters. The absolute increased gene expression level of CLDN16 was significantly negatively correlated with estrogen $(\mathrm{r}=-0.46 ; \mathrm{p}<0.0001)$ and progesterone receptor $(\mathrm{r}=-0.384 ; \mathrm{p}=0.001)$ staining density. However, a significantly positive correlation $(\mathrm{r}=0.24 ; \mathrm{p}=0.04)$ between the absolute increased HAPLN3 gene level and human epidermal receptor 2 staining density was found. There was no significant association between overall survival and the two gene expression levels. The gene up-expression of both CLDN16 and HAPLN3 was suggested to be involved
\end{abstract}

Correspondence to: Professor Dar-Ren Chen, Comprehensive Breast Cancer Center, Changhua Christian Hospital, No. 135 Nanhsiao Street, Changhua 500, Taiwan

E-mail: darren_chen@cch.org.tw

Dr Hsiu-Ting Tsai, School of Nursing, Chung Shan Medical University, No. 110, Sec. 1, Chien-Kuo N. Road, Taichung 40201, Taiwan

E-mail: tsaihsiuting@yahoo.com.tw

Key words: CLDN16, HAPLN3, breast cancer, gene expression in the development of breast cancer and to be a biomarker and target treatment for breast cancer.

\section{Introduction}

Breast cancer, an epithelial tumor with highly invasive and metastatic potential, is one of the most frequently occurring malignant neoplasms worldwide $(1,2)$, and is the fourth leading cause of cancer death among Taiwanese in Taiwan (3). Mammography screening is used for detection of certain lesions which are considered to be precursors of invasive breast cancer, such as ductal carcinoma in situ and atypical ductal hyperplasia (2). Recently, hormone-related factors such as estrogen receptor (ER), progesterone receptor (PR), and human epidermal receptor 2 (HER2) have been considered to be associated with the development and prognosis of breast cancer and suggested to be predictors for response to treatment of breast cancer (4-7). However, poor agreement on these predictors in the detection and prediction of breast cancer development limits their generalizability in clinical application. Therefore, additional biological and clinical studies on their significance in the diagnosis and therapy of breast cancer are strongly suggested.

During cancer development, the destruction of tight junctions (8), as well as the deprivation of cell polarity $(9,10)$ and increased cell mobility $(11,12)$, contribute to cancer cell proliferation, invasion, and metastasis, and a poor prognosis. Claudin-16 (CLDN16), a member of the claudins family, is a tight junction protein and plays important roles in the maintenance of cell polarity, cellular arrangement, adhesion, paracellular transport, and ionic permeability of various epithelia (13-16). Up-expressions of claudin-16 were found in human tissues with ovarian cancer (17) and papillary thyroid carcinomas (18). Moreover, a novel link protein, HAPLN3, belonging to the hyaluronan and proteoglycan link protein family, functions in the aggregation of proteoglycan with hyaluronic acid and cell adhesion $(17,19)$. In the HAPLN family, HAPLN3 is the most abundant and widely expressed in most tissue, including that of the mammary gland, ovary, lymph node, spleen, thymus, heart and lung $(19,20)$, and is believed to play an important role in the construction and stabilization of hyaluronan-dependent extracellular matrix (19). It has been reported that proteoglycan promotes cancer cell mobility and migration through signal transduction by 
binding to cell membrane, which relies on the migratory pathway created by migrating cells themselves and cells of their surrounding tissues, and the connection of proteoglycan and hyaluronan by HAPLN (11). This suggests that overexpression of CLDN16 and HAPLN3 may be related to breast cancer development and metastasis.

The roles of CLDN16 and HAPLN3 in the development of breast cancer have not been fully clarified. We collected 146 samples from breast cancer tissues and their adjacent normal breast tissues to estimate the gene expressions of CLDN 16 and HAPLN3 between non-cancer and cancer tissues using reverse transcription (RT) and real-time polymerase chain reaction (real-time $\mathrm{PCR}$ ). The association among the expression of both genes, clinicopathological parameters, hormone-related factors, and overall survival of breast cancer patients in relation to increased CLDN16 or HAPLN3 gene expression was also evaluated.

\section{Materials and methods}

Subjects and specimen collection. Seventy-three patients with breast infiltrating ductal carcinoma were recruited for our study, and the breast tissue specimens were obtained from patients who underwent surgical treatment at the Department of Surgery at Changhua Christian Hospital between 2002 and 2007. One hundred and forty-six tissue specimens, collected from breast cancer tissues and their adjacent normal breast tissues, were immediately frozen in liquid $\mathrm{N} 2$ and stored at $-80^{\circ} \mathrm{C}$ until further analysis. The histological types of the primary tissues and the clinicopathological stage of the breast cancer were determined by pathology, according to a system based on a modification of the WHO classification and the TNM system, respectively. Associated clinicopathological characteristics, such as clinical stage of breast cancer, cell differentiation status, lymph node metastasis, and distant metastasis, were verified by chart review. The study was performed with the approval of the Changhua Christian Hospital Institutional Review Board and informed written consent was obtained from each individual.

Tissues RNA extraction. Total RNA were extracted from frozen breast cancerous tissues and their adjacent normal breast tissues using RNA zol-B (RNA-Bee ${ }^{\mathrm{TM}}$, Tel-Test, Protech Technology Enterprise Co., Ltd., USA), following the instructions in the manual. Tissue samples were homogenized in RNA-Bee. Chloroform was added per $1 \mathrm{ml}$ of RNA-Bee, was vigorously shaken for 15-30 min, and then centrifuged at $4^{\circ} \mathrm{C}$. The aqueous phase was transferred to a clean tube, isopropanol added, and the samples stored overnight at $-20^{\circ} \mathrm{C}$. Then, the samples were centrifuged at $12,000 \mathrm{x} \mathrm{g}$ for $5 \mathrm{~min}$ at $4^{\circ} \mathrm{C}$. RNA precipitate formed a white-yellow pellet at the bottom of the tube. The supernatant was removed and the RNA pellet was washed once with $75 \%$ ethanol, and then was centrifuged at 7,500 x g for $5 \mathrm{~min}$ at $4^{\circ} \mathrm{C}$, and this wash process was repeated twice. At the end of the procedure, the RNA pellet was air-dried briefly for 5-10 min, and then was dissolved in diethyl pyrocarbonate- $\mathrm{H}_{2} \mathrm{O}$ and stored at $-80^{\circ} \mathrm{C}$ until reverse transcription.
Generation of $c D N A$. Total RNA was used to prepare complementary DNA (cDNA) using RT. The reaction mixtures contained RNA, Oligo $(\mathrm{dT})_{15}$ (Promega, USA) and random primer (Protech Technology Enterprise Co., Ltd.); the volume was adjusted with DEPC- $\mathrm{H}_{2} \mathrm{O}$, heated at $70^{\circ} \mathrm{C}$ for $5 \mathrm{~min}$, and placed on ice for $3 \mathrm{~min}$. Then, reverse transcriptase mixtures which contained MMLV (Protech Technology Enterprise Co., Ltd.), dNTPs (Protech Technology Enterprise Co., Ltd.). DTT (Protech Technology Enterprise Co., Ltd.), and rRNasin (human ribonuclease inhibitor, Protech Technology Enterprise Co., Ltd.) were added. The reaction was incubated at $37^{\circ} \mathrm{C}$ for $4 \mathrm{~h}$. The concentration of cDNA was measured by spectrophotometer (BioPhotometer 6131, Eppendorf, Germany) and adjusted to $150 \mathrm{ng} / \mathrm{ml}$ for real-time PCR.

Quantitative real-time PCR analysis. CLDN16 and HAPLN3 genes were quantitatively examined for expression levels by real-time PCR using the TaqMan probe real-time PCR assay (Roche Diagnostic, Germany). Homo sapiens ribosomal protein S18 (RPS18) was used in the study as an endogenous control gene. Two of the most commonly used endogenous control genes for breast cancer gene expression studies are glyceraldehydes-3-phosphate dehydrogenase (GAPDH) and $B$-actin (ACTB). The following primer pairs were used for CLDN16 and HAPLN3 gene transcripts: CLDN16 (forward primer, 5'-CTGGGTCTCTGGGTTGCTTT-3'; reverse primer, 5'-TTTCTCTCAGGTCCAACATCTTT-3'; amplicon length 82 bp), HAPLN3 (forward primer, 5'-TTACCGCTGTGAG GTCATTG-3'; reverse primer, 5'-GGGACTGGTAAGGA AAGACCA-3'; amplicon length 89 bp). The amplification of the target genes was as follows: $95^{\circ} \mathrm{C} 10 \mathrm{~min}$, followed by 50 cycles of $95^{\circ} \mathrm{C}$ for $15 \mathrm{sec}$ and $58^{\circ} \mathrm{C}$ for $1 \mathrm{~min}$. Each sample was calculated by three repeated analyses.

Immunohistochemistry analysis. Gene expression of ER, PR, and HER2 in cancerous tissue was analyzed based on standard immunohistochemistry. Immunostaining was performed with anti-ER (Dako, ID5), anti-PR (Dako, PGR 636), and anti-HER2 (Dako, Carpinteria, CA), respectively, using an autostaining and semiquantitative scoring system (Ventana Medical System, Inc., AZ, USA). The status of hormone-related receptors was evaluated according to breast pathology guidelines. For estimation of ER and PR gene expression, analysis in which a value was $<10 \%$ of expression was considered as a negative staining for hormone receptor, and a percentage of expression equal to or $>10 \%$ of expression was considered as a positive staining. An expression percentage between $10 \%$ and $<50 \%$ was scored as grade 1 , between 50 and $75 \%$ was scored grade 2 , and $>75 \%$ was scored grade 3 . In the assessment of the staining of HER2, no staining or membrane staining $<10 \%$ of invasive tumor cells was considered a negative and scored grade 0 ; a barely perceptive membrane staining detected in $>10 \%$ of invasive tumors was also considered a negative staining and scored grade 1; a weak to moderate complete membrane staining in $>10 \%$ of invasive tumor cells or $<30 \%$ with strong complete membrane staining was considered an equivocal staining and scored grade 2; a strong complete membrane staining in $>30 \%$ of invasive tumor cells was considered a positive 
Table I. Comparison of gene expressions of CLDN16 and HAPLN3 in tumor tissues and normal tissues of 73 patients with breast cancer.

\begin{tabular}{|c|c|c|c|c|c|c|c|}
\hline \multirow[b]{2}{*}{ Gene } & \multicolumn{3}{|c|}{ Normal tissues $(n=73)$} & \multicolumn{3}{|c|}{ Tumor tissues $(\mathrm{n}=73)$} & \multirow[b]{2}{*}{$\mathrm{P}$-value } \\
\hline & Mean \pm SE & Min, Med, Max & $\begin{array}{c}\mathrm{CV} \text { of } \\
\text { intra-assay }(\%)\end{array}$ & Mean \pm SE & Min, Med, Max & $\begin{array}{c}\mathrm{CV} \text { of } \\
\text { intra-assay }(\%)\end{array}$ & \\
\hline CLDN16 & $0.59 \pm 0.26$ & $0.00,0.00,11.25$ & 5.95 & $8.29 \pm 0.82$ & $0.00,10.49,18.92$ & 14.75 & $\mathrm{p}<0.0001$ \\
\hline HAPLN3 & $3.76 \pm 0.57$ & $0.00,0.00,13.64$ & 13.19 & $8.84 \pm 0.58$ & $0.00,10.41,17.29$ & 6.28 & $\mathrm{p}<0.0001$ \\
\hline
\end{tabular}

The significant differences were analyzed using the Wilcoxon signed-rank test. p-value $<0.05$ was considered significant. Min, minimum; Med, median; Max, maximum; CV of intra-assay, the variation coefficients of intra-assay.

staining and scored grade 3 . In score $2+$ cases, fluorescent in situ hybridization was performed and the HER2 status was judged on this basis.

Statistical analysis. Experimental results are presented as the mean $\pm \mathrm{SE}$, minimum, median, and maximum. The variation coefficients of the intra-assay were estimated for the validation of precision. A non-parametric method was used since the distribution of experimental results was not normal for some variables. A Wilcoxon signed-ranks test was used for evaluation of gene expression in normal and tumor tissues of patients with breast cancer. The comparison of absolute increased gene expression levels between two compared clinical stages was estimated using the Mann-Whitney U test. The correlations were examined with Spearman's rank correlation. The Kaplan-Meier curve model was used for univariate analysis to identify factors most significantly related to overall survival (December 31, 2008). A p-value $<0.05$ was considered significant. The data were analyzed using SPSS version 13.0 (SPSS Inc., Chicago, IL, USA) statistical software.

\section{Results}

Gene expression profiles of CLDN16 and HAPLN3 in tumor tissues versus normal tissues. The mean age $( \pm \mathrm{SE})$ of our 73 recruited patients with breast cancer was $58.68 \pm 1.50$ years. The gene expression profiles of CLDN16 and HAPLN3 were determined in tumor tissues with breast cancer, and compared with their adjacent normal breast tissues. Triplicate experiments were carried out for each pair of RNA samples to minimize technical variations and for statistical analysis. The experimental results of mean $\pm \mathrm{SE}$, minimum, median, and maximum, and the variation coefficients of the intraassays are shown in Table I. There were significantly increased gene expression (mean \pm SE) of CLDN16 (normal tissues, $0.59 \pm 0.26$; tumor tissue, $8.29 \pm 0.82 ; \mathrm{p}<0.0001$ ) and HAPLN3 (normal tissues, 3.76 \pm 0.57 ; tumor tissue, $8.84 \pm 0.58$; $p<0.0001$ ) among breast cancer samples compared with their adjacent normal breast tissues.

The comparisons of gene expression levels between tumor tissues and normal tissues in different clinical stages. The significantly different gene expression levels of CLDN16 and HAPLN3 in tumor tissues compared with normal tissues were analyzed based on different clinical stage, respectively, and the results are shown in Table II. There were significantly increased gene expression levels of CLDN16 and HAPLN3 in breast tumor tissues compared with their adjacent normal breast tissues when we analyzed those based on different clinical stages, cell differentiation, lymph node metastasis, and distant metastasis.

The comparisons of absolute increased gene expression levels between different clinical statuses. The absolute increased gene expressions were estimated based on subtracting the gene expression levels of normal tissues from the levels of tumor tissues. The absolute increased gene expression levels (mean \pm SE) of CLDN16 were 7.42 \pm 0.93 in clinical stage $\leq$ II, $8.47 \pm 1.80$ in clinical stage $\geq \mathrm{III}, 6.90 \pm 1.04$ in good to moderate cell differentiation, $9.23 \pm 1.36$ in poor cell differentiation, $8.37 \pm 1.08$ in non-lymph node metastasis, $6.73 \pm 1.29$ in lymph node metastasis, $7.62 \pm 0.90$ in non-distant metastasis, and $8.15 \pm 2.32$ in distant metastasis of each separate group, respectively. In addition, the absolute increased gene expression levels of HAPLN3 were 4.59 $\pm 0.91,6.43 \pm 1.56,4.88 \pm 1.07$, $5.44 \pm 1.06,4.69 \pm 1.00,5.62 \pm 1.29,5.03 \pm 0.85$, and $5.33 \pm 2.14$ in each of the above ordinal classifications, respectively. Subsequently, the comparisons of absolute increased gene expression levels of CLDN16 and HAPLN3 between each paired clinical status, such as clinical stage $\leq$ II versus clinical stage (III, good to moderate cell differentiation versus poor cell differentiation, non-lymph node metastasis versus lymph node metastasis, and non-distant metastasis versus distant metastasis were analyzed, respectively. There was no significant difference in absolute increased gene expression levels between each paired comparison for both the CLDN16 gene (Fig. 1A) and the HAPLN3 gene (Fig. 1B).

The correlations between absolute increased gene expression levels and the intensity of hormone-related receptor staining. The correlations between absolute increased gene expression of CLDN16 and absolute increased HAPLN3, estrogen receptor staining density, and progesterone receptor staining density, as well as the correlation between absolute increased HAPLN3 and human epidermal receptor 2 staining density, 
Table II. Gene expressions of CLDN16 and HAPLN3 in tumor tissues and normal tissues of 73 patients with breast cancer in different clinical stages.

\begin{tabular}{|c|c|c|c|c|c|c|}
\hline \multirow[b]{2}{*}{ Variable } & \multirow[b]{2}{*}{ Gene } & \multicolumn{2}{|c|}{ Normal tissues $(n=73)$} & \multicolumn{2}{|c|}{ Tumor tissues $(n=73)$} & \multirow[b]{2}{*}{ P-value } \\
\hline & & Mean \pm SE & Min, Med, Max & Mean \pm SE & Min, Med, Max & \\
\hline \multirow{2}{*}{$\begin{array}{l}\text { Stage } \leq \mathrm{II} \\
(\mathrm{n}=54 ; 73.9 \%)\end{array}$} & CLDN16 & $0.80 \pm 0.35$ & $0.00,0.00,11.25$ & $8.23 \pm 0.93$ & $0.00,10.62,18.92$ & $\mathrm{p}<0.0001$ \\
\hline & HAPLN3 & $4.41 \pm 0.70$ & $0.00,0.00,13.64$ & $9.01 \pm 0.65$ & $0.00,10.30,17.29$ & $\mathrm{p}<0.0001$ \\
\hline \multirow{2}{*}{$\begin{array}{l}\text { Stage } \geq \text { III } \\
(n=19 ; 26.1 \%)\end{array}$} & CLDN16 & $0.00 \pm 0.00$ & $0.00,0.00,0.00$ & $8.47 \pm 1.80$ & $0.00,10.49,18.61$ & $\mathrm{p}=0.003$ \\
\hline & HAPLN3 & $1.91 \pm 0.81$ & $0.00,0.00,11.81$ & $8.34 \pm 1.30$ & $0.00,10.82,15.71$ & $\mathrm{p}=0.004$ \\
\hline \multirow{2}{*}{$\begin{array}{l}\text { Well to moderate } \\
\text { differentiation } \\
(n=48 ; 65.7 \%)\end{array}$} & CLDN16 & $0.36 \pm 0.26$ & $0.00,0.00,10.57$ & $7.26 \pm 1.07$ & $0.00,7.12,18.61$ & $\mathrm{p}<0.0001$ \\
\hline & HAPLN3 & $3.26 \pm 0.68$ & $0.00,0.00,13.64$ & $8.15 \pm 0.81$ & $0.00,9.98,17.29$ & $\mathrm{p}<0.0001$ \\
\hline \multirow{2}{*}{$\begin{array}{l}\text { Poor differentiation } \\
(\mathrm{n}=25 ; 34.3 \%)\end{array}$} & CLDN16 & $1.03 \pm 0.58$ & $0.00,0.00,11.25$ & $10.26 \pm 1.17$ & $0.00,11.33,18.92$ & $\mathrm{p}<0.0001$ \\
\hline & HAPLN3 & $4.72 \pm 1.04$ & $0.00,0.00,13.41$ & $10.17 \pm 0.60$ & $0.00,10.86,16.13$ & $\mathrm{p}<0.0001$ \\
\hline \multirow{2}{*}{$\begin{array}{l}\text { No lymph node } \\
\text { metastasis } \\
(n=43 ; 58.9 \%)\end{array}$} & CLDN16 & $0.59 \pm 0.34$ & $0.00,0.00,11.25$ & $8.97 \pm 1.03$ & $0.00,11.48,18.92$ & $\mathrm{p}<0.0001$ \\
\hline & HAPLN3 & $4.43 \pm 0.80$ & $0.00,0.00,13.64$ & $9.13 \pm 0.69$ & $0.00,10.41,17.29$ & $\mathrm{p}<0.0001$ \\
\hline \multirow{2}{*}{$\begin{array}{l}\text { Lymph node } \\
\text { metastasis } \\
(n=30 ; 41.1 \%)\end{array}$} & CLDN16 & $0.58 \pm 0.41$ & $0.00,0.00,10.57$ & $7.32 \pm 1.35$ & $0.00,8.26,18.61$ & $\mathrm{p}<0.0001$ \\
\hline & HAPLN3 & $2.80 \pm 0.78$ & $0.00,0.00,11.81$ & $8.42 \pm 1.03$ & $0.00,10.36,16.13$ & $\mathrm{p}=0.001$ \\
\hline \multirow{2}{*}{$\begin{array}{l}\text { No distant } \\
\text { metastasis } \\
(n=63 ; 86.3 \%)\end{array}$} & CLDN16 & $0.68 \pm 0.30$ & $0.00,0.00,11.25$ & $8.31 \pm 0.89$ & $0.00,10.13,18.92$ & $\mathrm{p}<0.0001$ \\
\hline & HAPLN3 & $4.09 \pm 0.63$ & $0.00,0.00,13.64$ & $9.13 \pm 0.62$ & $0.00,10.82,17.29$ & $\mathrm{p}<0.0001$ \\
\hline \multirow{2}{*}{$\begin{array}{l}\text { Distant metastasis } \\
(\mathrm{n}=10 ; 13.7 \%)\end{array}$} & CLDN16 & $0.00 \pm 0.00$ & $0.00,0.00,0.00$ & $8.15 \pm 2.32$ & $0.00,11.02,18.26$ & $\mathrm{p}=0.02$ \\
\hline & HAPLN3 & $1.68 \pm 1.14$ & $0.00,0.00,9.81$ & $7.01 \pm 1.63$ & $0.00,8.87,12.92$ & $\mathrm{p}=0.04$ \\
\hline
\end{tabular}

The significant differences were analyzed with the Wilcoxon signed-rank test. The p-value $<0.05$ was considered significant. Min, minimum; Med, median; Max, maximum.

are shown in Fig. 2. The significant correlations were $0.5(\mathrm{p}<0.0001)$ between absolute increased CLDN16 and HAPLN3, -0.46 ( $\mathrm{p}<0.0001)$ between absolute increased CLDN16 and estrogen receptor staining density, -0.384 $(p=0.001)$ between absolute increased CLDN16 and progesterone receptor staining density, and $0.24(\mathrm{p}=0.04)$ between absolute increased HAPLN3 and human epidermal receptor 2 staining density, respectively.

The association between overall survival and gene expression. During a mean follow-up of 53.8 months (range, 8.4-64.5), $11(15.1 \%)$ of the 73 patients had died. Overall survival was $84.9 \%$ in our 73 recruited patients, and in the subgroups, overall survival was 86.0 and $83.3 \%$ in the over- and nonoverexpression of CLDN16 subgroups, and 83.0 and $88.5 \%$ in the over and non-overexpression of HAPLN3 subgroups, respectively. The Kaplan-Meier method found no significant difference in overall survival distributions (CLDN16, $\mathrm{p}=0.75$; HAPLN3, $\mathrm{p}=0.52$, respectively) between the over- and non-overexpression subgroups of CLDN16 and HAPLN3 (Fig. 3).

\section{Discussion}

CLDN16 is a $36 \mathrm{kDa}$ tight junction protein which has four transmembrane domains and intercellular $\mathrm{N}$-and C-termini, and plays an important role in maintaining the polarity and barrier function of various epithelia (13-16,21). Recently, it has been hypothesized to play a role in carcinogenesis $(17,18,22)$. For breast epithelial cells, the role of the claudin family on breast cancer is still equivocal. Overexpression of CLDN4 was found in breast tumor cells compared to normal epithelial cells, irrespective of tumor size, presence or absence of lymph node metastasis, and histology type $(23,24)$. However, significant down-expression of CLDN2 was found in advanced breast carcinoma (25). In the present study, we found a significantly increased gene expression of CLDN16 in breast cancer tissues compared to their adjacent 
A

$\square$ Pathological stage

Tumor cell differentiation

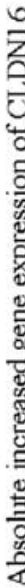

B

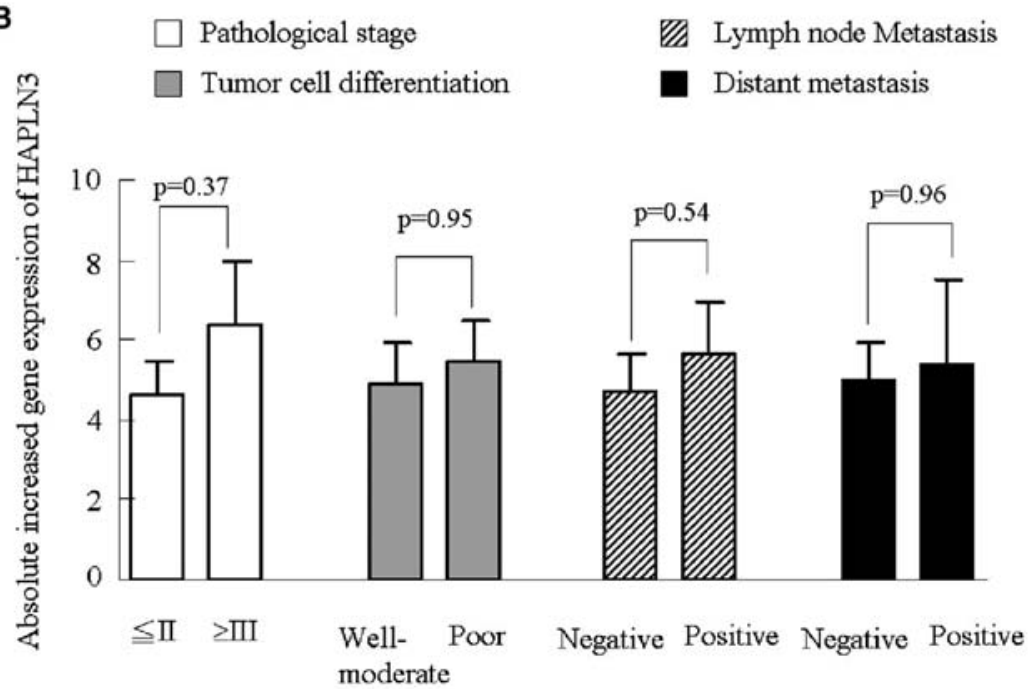

W Lymph node Metastasis

Distant metastasis

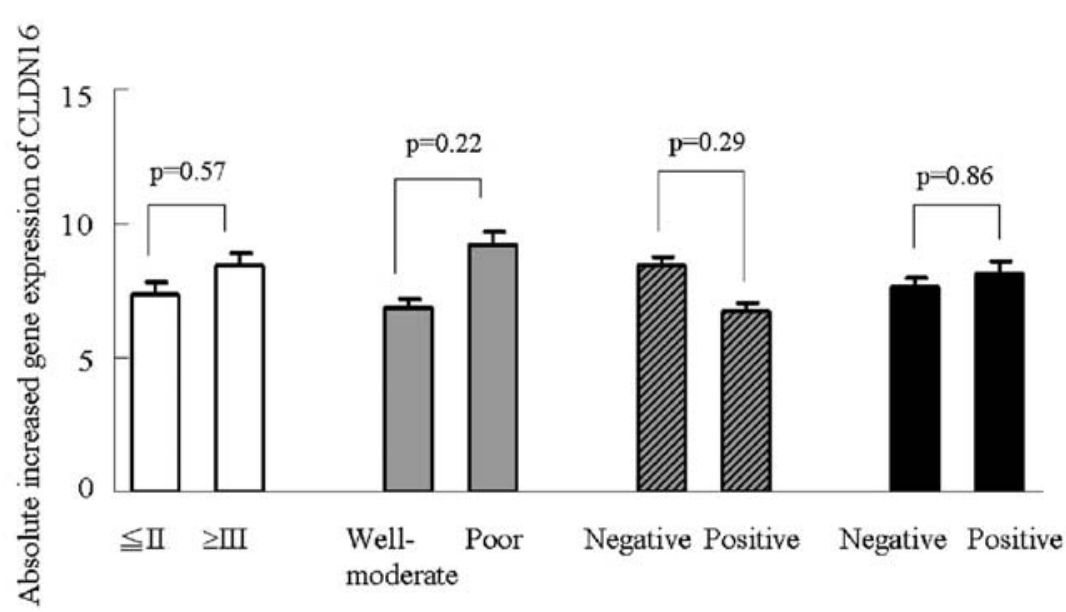

moderate

Figure 1. The comparisons of absolute increased gene expression levels of CLDN16 and HAPLN3 between two compared clinical stages were estimated using the Mann-Whitney U test. There was no significant difference of absolute increased gene expression levels between each paired comparison for either the CLDN16 gene (A) or the HAPLN3 gene (B).

normal breast tissues, irrespective of clinical pathological parameters, such as clinical stage, cell differentiation, lymph node metastasis, and distant metastasis among the 73 recruited subjects. Our results are similar to those of Rangel et $a l$ and Fluge et al. In their studies, they found upexpressions of CLDN16 in human tissues with ovarian cancer (17) and papillary thyroid carcinomas (18), respectively. Moreover, up-expression of CLDN16 was considered to be correlated with the alteration of cell polarity in dedifferentiated papillary thyroid carcinomas (18). To the best of our knowledge, only one study (26) has demonstrated that CLDN16 induced changes in cell morphology, increased trans-epithelial persistence, reduced paracellular permeability, and reduced the invasive phenotypes of human breast cancer cells after transfection of CLDN16 gene into those cells (27). The authors also carried out an immunohistological assay to estimate the degree of staining of CLDN16 using 10 pairs of matched human breast tissues (tumor and normal tissue), and found that the staining for
CLDN16 within the tumor sections was significantly decreased compared to normal tissues. However, they found no significantly different gene expression between tumor and normal tissue at the mRNA level using quantitative PCR. We consider that the small sample sizes of their study (28) was the reason for the conflicting result in their data and between their data and ours. Although the CLDN16 gene was transfected into the cell lines to investigate the possible mechanism of CLDN16-induced morphological change, phenomenon of gene transfection in an in vitro study is limited in fully revealing the fact phenomena of human breast tissue. Numerous other explanations for the different findings are possible, including genetic variance in different racial populations, different age distributions between the two studies, environmental factors, and interaction between CLDN16 and the linked gene.

Recently, link proteins have been considered to be associated with the mobility and migration of cancer cells (11). HAPLN3, a novel link protein, is widely found in 
A

Spearman correlation coefficient $\mathrm{r}=0.50, \mathrm{p}<0.0001, \mathrm{n}=73$

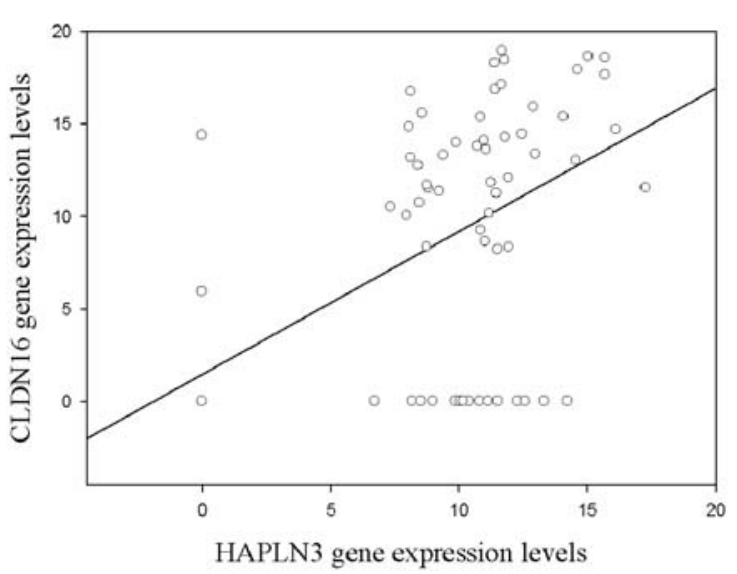

C

Spearman correlation coefficient

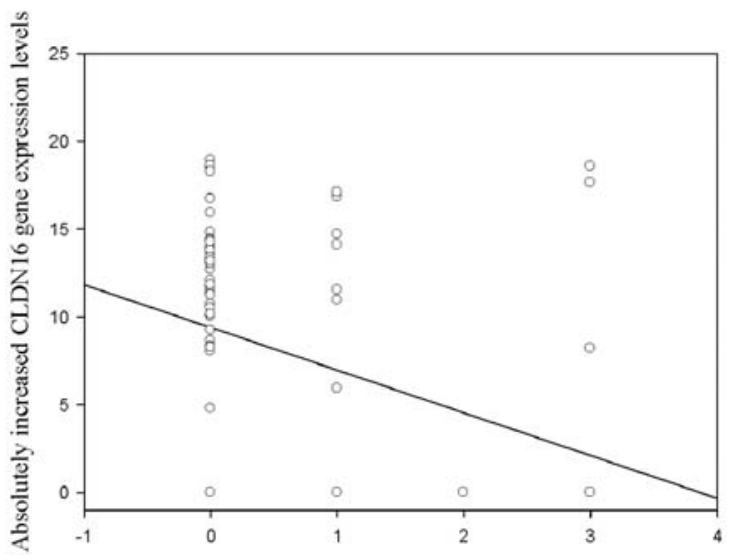

The grade of progesterone receptor staining densities
B Spearman correlation coefficient

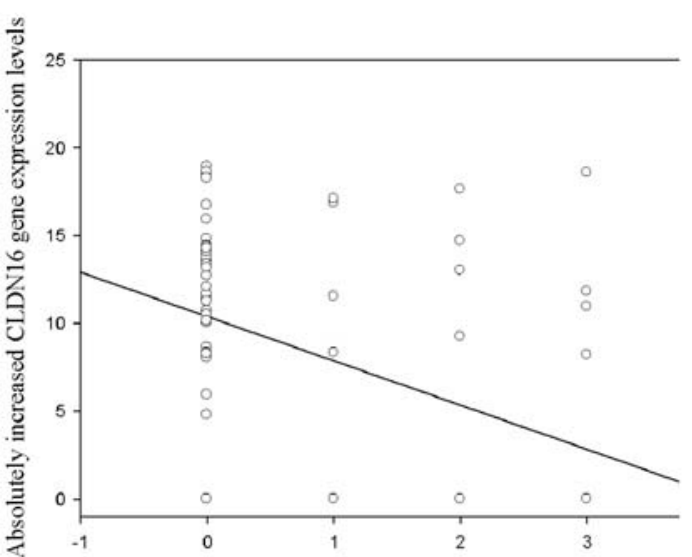

The grade of estrogen receptor staining densities

D

Spearman correlation coefficient $\mathrm{r}=0.24, \mathrm{p}=0.04, \mathrm{n}=73$

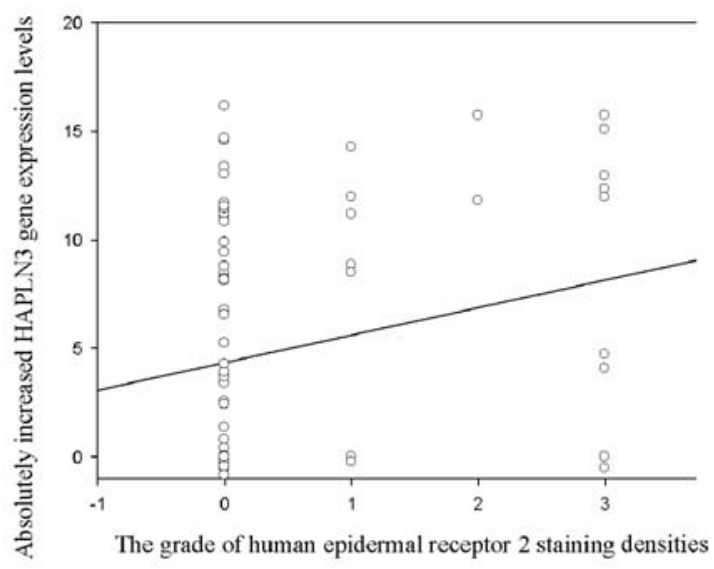

Figure 2. The significant correlations between each parameter were estimated using Spearman's rank correlation. (A) The significant correlation between CLDN16 and HAPLN3 $(r=0.5 ; \mathrm{p}<0.0001)$ gene expressions. (B) The significantly negative correlation between the absolute increased gene expression level of CLDN16 and estrogen receptor staining density $(\mathrm{r}=-0.46 ; \mathrm{p}<0.0001)$. (C) The significantly negative correlation between the absolute increased gene expression level of CLDN16 and progesterone receptor staining density ( $\mathrm{r}=-0.384 ; \mathrm{p}=0.001)$. (D) The significantly positive correlation between the absolute increased gene expression level of HAPLN3 and human epidermal receptor 2 staining density $(r=0.24 ; p=0.04)$.

A

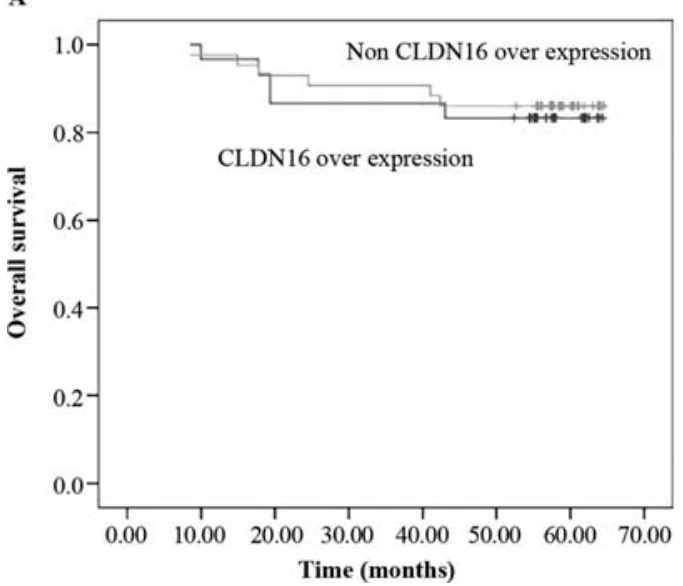

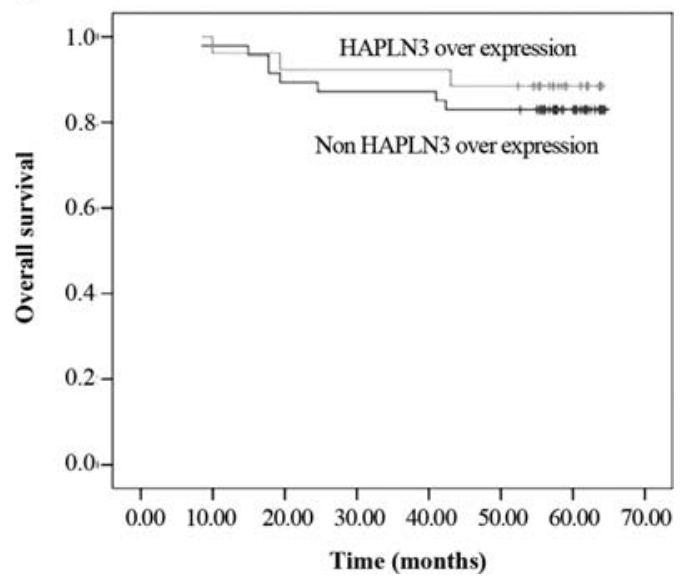

Figure 3. Kaplan-Meier curves for overall survival in patients with breast cancer based on over versus non-overexpression of CLDN16 (a, $\mathrm{p}=0.75)$ and HAPLN3 ( $b, p=0.52$ ), respectively. The log-rank test was used for statistical significance. 
mammary gland, ovary, lymph node, spleen, thymus, heart and lung tissues $(19,20)$. To our knowledge, this is the first study to investigate the role of HAPLN3 in breast cancer. We found that the HAPLN3 gene had significantly increased expression in breast cancer tissues compared to normal breast tissues, but was not associated with clinicopathological parameters, such as clinical stage, cell differentiation, lymph node metastasis, and distant metastasis. Moreover, the absolute increased gene expression level of HAPLN3 was significantly correlated with that of CLDN16. The role of HAPLN3 in carcinogenesis still remains to be determined. Only Ogawa et al have reported a coordinated up-regulation of HAPLN3 and versican by platelet-derived growth factor in primary cultured rat arterial smooth muscle cells (20). Versican, expressed in the extracellular matrix of epithelial and non-epithelial tumors, is a large chondroitin sulfate proteoglycan and is considered to play a role in the development of breast cancer by enhancement of cell proliferation, differentiation, adhesion, and migration, as well as having potential effects on angiogenesis (26-29). Moreover, it has been suggested that hyaluronan, conjugated with HAPLN3 for aggregating with proteoglycan, had significantly increased expression in malignant breast tumors, either through secretion of diffusible factors or cell-cell contact. Subsequently, the up-expression induced the accumulation of hyaluronan and contributed to cancer cell mobility by forming an expanded space, and enhanced tumor growth by inducing vascularization (30). We suggested that upexpression of HAPLN3 could contribute to the promotion of cell proliferation, migration, and angiogenesis by cooperation with versican or hyaluronan. Moreover, overexpression of CLDN16 dominated the alteration of cell polarity in breast cancer $(9,18,31)$, and mutual up-expression of both CLDN16 and HAPLN3 could contribute to the development of breast cancer, although those mechanisms require further clarification.

The role of hormone-related receptors in breast cancer is still controversial. Nevertheless, it has been demonstrated that an invasive grade of breast cancer was negatively correlated to ER and PR expression $(23,31,32)$, but positively correlated with HER2 expression $(33,34)$. Similar to MunozGuerra et al (22) and Lanigan et al (24), we found that the absolute increased gene expression level of CLDN16 was significantly negatively correlated with estrogen and progesterone receptor staining density. However, a significantly positive correlation between absolute increased HAPLN3 and human epidermal receptor 2 staining density, and an insignificant association between overall survival and both gene expression levels were found.

In view of this study, up-regulation of both CLDN16 and HAPLN3 is suggested to be involved in the development of breast cancer. Despite the fact that the exertion of both genes on breast cancer is unclear, we have provided a novel finding for further application in the biomarker and targeted treatment of breast cancer.

\section{Acknowledgements}

This study was supported by a research grant from Changhua Christian Hospital and Chung Shan University, Taichung, Taiwan (097-CCH-CSMU-12).

\section{References}

1. Saez RA, McGuire WL and Clark GM: Prognostic factors in breast cancer. Semin Surg Oncol 5: 102-110, 1989.

2. Schnitt SJ: The diagnosis and management of pre-invasive breast disease: flat epithelial atypia-classification, pathologic features and clinical significance. Breast Cancer Res 5: 263-268, 2003.

3. Department of Health ROC: Health Statistics: II. Vital Statistics. Department of Health, Republic of China, 2008.

4. Huang WY, Newman B, Millikan RC, Schell MJ, Hulka BS and Moorman PG: Hormone-related factors and risk of breast cancer in relation to estrogen receptor and progesterone receptor status. Am J Epidemiol 151: 703-714, 2000.

5. Fernandez-Morales LA, Segui MA, Andreu X, et al: Analysis of the pathologic response to primary chemotherapy in patients with locally advanced breast cancer grouped according to estrogen receptor, progesterone receptor, and HER2 status. Clin Breast Cancer 7: 559-564, 2007.

6. Iwase H, Kurebayashi J, Tsuda H, et al: Clinicopathological analyses of triple negative breast cancer using surveillance data from the Registration Committee of the Japanese Breast Cancer Society. Breast Cancer 17: 118-124, 2010.

7. Kwan ML, Kushi LH, Weltzien E, et al: Epidemiology of breast cancer subtypes in two prospective cohort studies of breast cancer survivors. Breast Cancer Res 11: R31, 2009.

8. Naik MU, Naik TU, Suckow AT, Duncan MK and Naik UP: Attenuation of junctional adhesion molecule-A is a contributing factor for breast cancer cell invasion. Cancer Res 68: 2194-2203, 2008.

9. Fournier MV, Fata JE, Martin KJ, Yaswen P and Bissell MJ: Interaction of E-cadherin and PTEN regulates morphogenesis and growth arrest in human mammary epithelial cells. Cancer Res 69: 4545-4552, 2009.

10. Humar B and Guilford P: Hereditary diffuse gastric cancer: a manifestation of lost cell polarity. Cancer Sci 100: 1151-1157, 2009.

11. Cattaruzza S and Perris R: Proteoglycan control of cell movement during wound healing and cancer spreading. Matrix Biol 24: 400-417, 2005

12. Afify A, Purnell P and Nguyen L: Role of CD44s and CD44v6 on human breast cancer cell adhesion, migration and invasion. Exp Mol Pathol 86: 95-100, 2009.

13. Himmerkus N, Shan Q, Goerke B, Hou J, Goodenough DA and Bleich M: Salt and acid-base metabolism in claudin-16 knockdown mice: impact for the pathophysiology of FHHNC patients. Am J Physiol Renal Physiol 295: F1641-F1647, 2008.

14. Hou J, Renigunta A, Konrad M, et al: Claudin-16 and claudin19 interact and form a cation-selective tight junction complex. J Clin Invest 118: 619-628, 2008.

15. Gunzel D, Haisch L, Pfaffenbach S, et al: Claudin function in the thick ascending limb of Henle's loop. Ann N Y Acad Sci 1165: 152-162, 2009

16. Shan Q, Himmerkus N, Hou J, Goodenough DA and Bleich M: Insights into driving forces and paracellular permeability from claudin-16 knockdown mouse. Ann N Y Acad Sci 1165: 148-151, 2009.

17. Rangel LB, Sherman-Baust CA, Wernyj RP, Schwartz DR, Cho KR and Morin PJ: Characterization of novel human ovarian cancer-specific transcripts (HOSTs) identified by serial analysis of gene expression. Oncogene 22: 7225-7232, 2003.

18. Fluge O, Bruland O, Akslen LA, Lillehaug JR and Varhaug JE: Gene expression in poorly differentiated papillary thyroid carcinomas. Thyroid 16: 161-175, 2006.

19. Spicer AP, Joo A and Bowling RA Jr: A hyaluronan binding link protein gene family whose members are physically linked adjacent to chondroitin sulfate proteoglycan core protein genes: the missing links. J Biol Chem 278: 21083-21091, 2003.

20. Ogawa H, Oohashi T, Sata M, et al: Lp3/Hapln3, a novel link protein that co-localizes with versican and is coordinately upregulated by platelet-derived growth factor in arterial smooth muscle cells. Matrix Biol 23: 287-298, 2004.

21. Weiss FU, Behn CO, Simon P, Ruthenburger M, Halangk W and Lerch MM: Cathepsin B gene polymorphism Val26 is not associated with idiopathic chronic pancreatitis in European patients. Gut 56: 1322-1323, 2007

22. Munoz-Guerra MF, Fernandez-Contreras ME, Moreno AL, Martin ID, Herraez B and Gamallo C: Polymorphisms in the hypoxia inducible factor 1-alpha and the impact on the prognosis of early stages of oral cancer. Ann Surg Oncol 16: 2351-2358, 2009. 
23. Kulka J, Szasz AM, Nemeth Z, et al: Expression of tight junction protein claudin-4 in Basal-like breast carcinomas. Pathol Oncol Res 15: 59-64, 2009.

24. Lanigan F, McKiernan E, Brennan DJ, et al: Increased claudin-4 expression is associated with poor prognosis and high tumour grade in breast cancer. Int J Cancer 124: 2088-2097, 2009.

25. Kim HO, Jo YH, Lee J, Lee SS and Yoon KS: The C1772T genetic polymorphism in human HIF-1alpha gene associates with expression of HIF-1alpha protein in breast cancer. Oncol Rep 20: 1181-1187, 2008

26. Ricciardelli C, Brooks JH, Suwiwat S, et al: Regulation of stromal versican expression by breast cancer cells and importance to relapse-free survival in patients with node-negative primary breast cancer. Clin Cancer Res 8: 1054-1060, 2002.

2.7 Suwiwat S, Ricciardelli C, Tammi R, et al: Expression of extracellular matrix components versican, chondroitin sulfate, tenascin, and hyaluronan, and their association with disease outcome in node-negative breast cancer. Clin Cancer Res 10: 2491-2498, 2004.

28. Yee AJ, Akens M, Yang BL, et al: The effect of versican G3 domain on local breast cancer invasiveness and bony metastasis. Breast Cancer Res 9: R47, 2007.
29. Bhardwaj A, Frankel WL, Pellegata NS, Wen P and Prasad ML: Intracellular versican expression in mesenchymal spindle cell tumors contrasts with extracellular expression in epithelial and other tumors, a tissue microarray-based study. Appl Immunohistochem Mol Morphol 16: 263-266, 2008.

30. Auvinen PK, Parkkinen JJ, Johansson RT, et al: Expression of hyaluronan in benign and malignant breast lesions. Int $\mathrm{J}$ Cancer 74: 477-481, 1997.

31. Lee HD, Koo JY and Jung WH: Correlations of bcl-2 expression with clinicopathological features in breast cancer. Yonsei Med J 38: 206-211, 1997.

32. Mohammadizadeh F, Naimi A, Rajabi P, Ghasemibasir H and Eftekhari A: Expression of basal and luminal cytokeratins in breast cancer and their correlation with clinicopathological prognostic variables. Indian J Med Sci 63: 152-162, 2009.

33. Tsuda H: Gene and chromosomal alterations in sporadic breast cancer: correlation with histopathological features and implications for genesis and progression. Breast Cancer 16: 186-201, 2009.

34. Roses RE, Paulson EC, Sharma A, et al: HER-2/neu overexpression as a predictor for the transition from in situ to invasive breast cancer. Cancer Epidemiol Biomarkers Prev 18: 1386-1389, 2009. 